\title{
A ECONOMIA CRIATIVA E O TURISMO: UMA ANÁLISE DO PROJETO SOUCURITIBA, DE CURITIBA-PARANÁ-BRASIL
}

THE CREATIVE ECONOMY AND TOURISM: AN ANALYSIS OF THE SOUCURITIBA PROJECT, FROM CURITIBA-PARANÁ-BRAZIL

\section{Thays Cristina Domareski Ruiz}

Doutora em Geografia pela Universidade Federal do Paraná

Professora e pesquisadora do Departamento de Turismo da Universidade Federal do Paraná.

E-mail: thaysruiz@ufpr.br.

\section{Graziela Scalise Horodyski}

Doutora em Geografia pela Universidade Federal do Paraná.

Professora do Departamento de Turismo da Universidade Estadual de Ponta Grossa.

E-mail: grazi.tur@gmail.com.

\section{Izamara Vanessa Carniatto}

Mestra em design pela Universidade Federal do Paraná.

E-mail: izamaracarniatto@gmail.com. 


\section{RESUMO}

Economia criativa é o conjunto de atividades econômicas que dependem do conteúdo simbólico, a matériaprima para a geração de serviços e produtos, sejam estes tangiveis ou intangiveis. Este conceito ganhou destaque como área de estudo a partir dos anos 2000. As indústrias criativas podem reforçar a cultura como valores que identificam uma comunidade, além do papel de coesão social e inclusão, com o potencial de gerar atratividade turística. Esta é a maneira pela qual a economia criativa se relaciona com a cultura e com o turismo. $\mathrm{O}$ objetivo deste estudo é analisar como a economia criativa se relaciona com o turismo a partir do fomento ao desenvolvimento de souvenirs em Curitiba. A metodologia apresenta uma abordagem qualitativa com análise descritiva e analítica da estratégia do Projeto SouCuritiba, desenvolvido a partir da parceria entre o Serviço de Apoio às Micro e Pequenas Empresas do Paraná (SEBRAE), a Fundação Cultural de Curitiba, o Instituto Municipal de Turismo de Curitiba, o Curitiba Região e Litoral Convention \& Visitors Bureau, o Centro Brasil Design e a Universidade Federal do Paraná, relacionando o turismo, a cultura e o design. Como resultados se apresentam a capacitação de mais de 140 empreendedores criativos e a geração de oportunidades de negócios que resultaram em mais de 900 mil reais em vendas no mercado turístico.

Palavras-chave: Economia criativa. Souvenir. Turismo. Curitiba-PR. Projeto SouCuritiba.

\section{ABSTRACT}

The creative economy is the set of economic activities that depend on the symbolic content, the raw material for the generation of services and products, whether tangible or intangible. This concept gained prominence as a study area from the 2000s. Creative industries can reinforce culture as values that identify a community, as well as the role of social cohesion and inclusion, with the potential to generate tourism attractiveness. This is the way the creative economy relates to culture and tourism. The objective of this paper is to analyse how the creative economy refers to tourism through the promotion of the development of souvenirs in Curitiba. The methodology presents a qualitative approach with a descriptive and analytical analysis of the strategy of the SouCuritiba Project. Developed from the partnership between the Service of Support to Micro and Small Companies of Paraná (SEBRAE), the Cultural Foundation of Curitiba, the Municipal Institute of Tourism Curitiba, Curitiba Region and Litoral Convention \& Visitors Bureau, the Brasil Design Center and the Federal University of Paraná relating tourism, culture and design. The results show the capacitation of more than 140 creative entrepreneurs and the generation of business opportunities that resulted in more than 900 thousand reais in sales in the tourist market.

Keywords: Creative economy. Souvenir. Tourism. Curitiba-PR. Project SouCuritiba. 


\section{INTRODUÇÃO}

O termo Economia Criativa ganhou repercussão em 2001 no livro de John Howkins sobre um termo síntese para diversos movimentos mundiais que relacionavam criatividade e economia. 0 relacionamento entre criatividade e economia surge de um conceito amplo que abrange 15 indústrias que vão desde 0 setor artístico até os setores da ciência e da tecnologia (HOWKINS, 2001; UNCTAD, 2010).

Em 1994, a Austrália foi precursora na tentativa de se posicionar como uma nação criativa, dando ênfase à sua diversidade cultural como o caminho para a geração de oportunidades. Na mesma direção, em 1997, o Reino Unido coloca a criatividade como o centro da estratégia econômica do país. A análise de tendências internacionais com as vocações internas fez surgir as primeiras definições dos setores criativos então definidos sob a ótica das Indústrias Criativas (REIS, 2012).

A United Nations Educational, Scientific and Cultural Organization (UNESCO) criou a Rede de Cidades Criativas em 2004, com o propósito de requalificar os espaços urbanos para o reconhecimento e difusão de novas práticas culturais e novos investimentos econômicos, que possam gerar riquezas socioeconômicas e culturais. As cidades criativas são ambientes diferenciados, pois são mais dinâmicas, interativas e atrativas (LANDRY, 2013).

Nos últimos anos, a requalificação dos espaços ganhou destaque, movida em alguns casos pela necessidade de encontrar soluções para contextos urbanos, em outros, motivada pela vontade de transformar o contexto atual. Sobre esse pano de fundo surgem propostas de revisões urbanas com as mais diversas adjetivações: cidades criativas, cidade inteligentes, cidades digitais, cidades inovadoras e até cidades emocionais (REIS, 2011).

A sociedade contemporânea vem se transformando rapidamente e seu desenvolvimento acelerado se reflete no conhecimento, na cultura e na criatividade como pilares fundamentais para a competitividade dos negócios e das cidades (ASHTON; TOMAZZONI; EMMENDOERFER, 2014; ASHTON, 2018).

Dessa forma, a economia criativa (HOWKINS, 2001; FLORIDA, 2002; UNCTAD, 2010; CAIADO, 2011), a indústria criativa (FLORIDA, 2002), as cidades criativas (REIS; KAGEYAMA, 2009; REIS, 2011; FLORIDA, 2002; REIS, 2012; VIVANT, 2012; ASHTON, 2018) e o turismo criativo (ASHTON, 2018; CHIM-MIKI; DOMARESKI-RUIZ, 2018) são termos que surgiram e passaram a ser destaque nas discussões mundiais, evidenciando a cultura da criatividade como pilar do desenvolvimento (ASHTON, 2018), onde:

0 advento da economia criativa impõe novas formas de organização nos modos de produção e de consumo, refletindo-se em todos os níveis socioeconômicos em âmbito mundial. Novas formas de relações de trabalho, de emprego, de estilos de vida têm reflexo também no setor turístico, demandando adequações e adaptações na produção e no consumo dos produtos e dos serviços de interesse do turismo (ASHTON, 2018, p. 19). 
Como um dos maiores e mais crescentes setores socioeconômicos, o turismo estimula o crescimento econômico, cria empregos e oportunidades de negócios, ajudando pessoas a escapar da pobreza e melhorar seus meios de subsistência. O turismo é também um dos setores mais resilientes a situações de crise e pode ainda atuar como catalisador de proteção ambiental e cultural (OMT, 2018).

As cidades criativas são fruto das transformações socioeconômicas, políticas e culturais em nível mundial e intensificadas pelo aumento da população nas zonas urbanas (ASHTON, TOMAZZONI, EMMENDOERFER, 2014), onde todo esse processo de transformação da sociedade provocou mudanças nos estilos de vida da população, refletindo em novos modos de produção e de consumo de bens e serviços turísticos que têm demandando novos moldes de destinos turísticos (ASHTON, 2018).

Estas cidades utilizam o capital cultural criativo da sociedade, promovendo novos arranjos, criando novos produtos e gerando novos consumos (MIRANDA, 2009), além de valorizar a história e a cultura da população, e são constituídas de elementos de criatividade e de inovação, baseadas no conhecimento humano, como fator gerador de economia e de qualidade de vida nos centros urbanos (LANDRY, 2013).

Um número crescente de cidades no mundo passa a direcionar investimentos para serem enquadradas como cidades criativas, valendo-se do diferencial para o desenvolvimento e crescimento, articulando o capital cultural com as atividades que envolvem o conhecimento humano criativo (FLORIDA, 2002; EMMENDOERFER; ASHTON, 2014), onde destaca-se a importância do turismo entre os fatores geradores de desenvolvimento, porque os turistas vêm em busca de consumo de produtos culturais, gerando, desse modo, um ambiente decisivo no desenvolvimento regional. Dessa forma, as cidades criativas se tornam alvo dos turistas na atualidade, pois a atmosfera composta pela diversidade cultural das cidades criativas atrai grandes fluxos turísticos, em razão da geração de produtos e de serviços diferenciados (ANDERSSON, 2005), onde o turismo criativo, com a proposta de consumir a experiência de uma vivência cultural local (RICHARDS, 2003), envolve uma mudança de valores na produção e no consumo turísticos (ASHTON, 2013).

Neste sentido, o objetivo deste estudo é analisar como a economia criativa fomenta o desenvolvimento de souvenirs em Curitiba. Serão descritos, na sequência, a metodologia do estudo e o referencial teórico, incluindo as temáticas de Turismo Criativo e Souvenir, abordando o objeto de estudo, o destino turístico Curitiba e o caso: Projeto SouCuritiba.

\section{METODOLOGIA}

A abordagem deste estudo é qualitativa, para isso utilizou-se como procedimentos metodológicos a pesquisa bibliográfica e documental, com análises descritivas e analíticas. A abordagem qualitativa, além 
de ser uma opção do investigador, justifica-se, sobretudo, por ser uma forma adequada de entender um fenômeno social (RICHARDSON, 1999). A vantagem da pesquisa de fonte bibliográfica reside no fato de permitir ao investigador a cobertura de uma gama de fenômenos muito mais ampla do que ele poderia pesquisar diretamente (GIL, 1999). Por meio da pesquisa bibliográfica foi possível reconhecer a temática da sazonalidade, onde todo este levantamento colaborou para ressaltar a relevância do tema proposto. A análise documental constitui uma técnica importante na pesquisa qualitativa, seja complementando informações obtidas por outras técnicas, seja revelando aspectos novos de um tema ou problema (LUDKE; ANDRÉ, 1986).

Quadro 01 - Resumo da Metodologia

\begin{tabular}{|c|c|c|}
\hline \multirow{4}{*}{$\begin{array}{l}\text { Etapa } 1 \\
\text { Pesquisa } \\
\text { Bibliogrăfica }\end{array}$} & Base de Dados & EBSCO; Science Direct; Scopus; \\
\hline & Bibliografia & $\begin{array}{l}\text { Dados Secundários: material bibliográfico de } 1990 \text { a } \\
\text { 2018; }\end{array}$ \\
\hline & $\begin{array}{l}\text { Estratégia de } \\
\text { Pesquisa }\end{array}$ & $\begin{array}{l}\text { Uso das palavras: economia da experiência; criatividade, } \\
\text { turismo; (português/espanhol/inglês); }\end{array}$ \\
\hline & Critério & No título, abstract ou palavras-chave; \\
\hline $\begin{array}{l}\text { Etapa } 2 \\
\text { Análise } \\
\text { Documental }\end{array}$ & Documentos & Dados Primários: Pesquisa Sou Curitiba; \\
\hline \multirow{2}{*}{$\begin{array}{l}\text { Etapa } 3 \\
\text { Análise } \\
\text { Descritiva e } \\
\text { Analítica }\end{array}$} & Análise & Descritiva e analítica; \\
\hline & Abordagem & Qualitativa; \\
\hline
\end{tabular}

Fonte: elaboração própria (2019)

\section{TURISMO CRIATIVO}

A economia criativa se caracteriza por potencializar o crescimento econômico, social e cultural de cidades através de um conjunto de ações baseadas no conhecimento, criatividade e inovação, que ampliam as possibilidades de desenvolvimento econômico local (UNCTAD, 2010; CAIADO, 2011; MEDEIROS, GRAND, FIGUEIREDO, 2011). Este conceito de economia criativa surge em meio a rápidas transformações 


\section{Gestãoe \\ Desenvolvimento}

da economia global, que podem ser sintetizadas pela intensificação da importância do conhecimento como recurso do sistema de produção.

A economia criativa é definida pela relação da criatividade com as ideias, onde as pessoas passam grande parte do tempo tendo ideias que geram produtos comercializáveis (HOWKINS, 2001; UNCTAD, 2010). A transição do abstrato ao prático é de difícil apreensão, porém, ocorre quando a ideia é identificada, aplicada e se torna um produto ou serviço, que deve atender a duas condições: resultar da criatividade e possuir reconhecido valor econômico. Tradicionalmente, bens diferenciam-se de serviços por serem tangiveis, mas a própria natureza do bem criativo implica forte componente simbólico e intangivel, presente, por exemplo, nos softwares, cujo valor físico é mínimo e representa, na realidade, apenas o suporte de um serviço (HOWKINS, 2001).

Os setores criativos que compõem a economia criativa estão divididos de acordo com suas características distintas. Esses quatro grupos, que são chamados de patrimônio, artes, mídia e criações funcionais, são descritos na figura 01. 


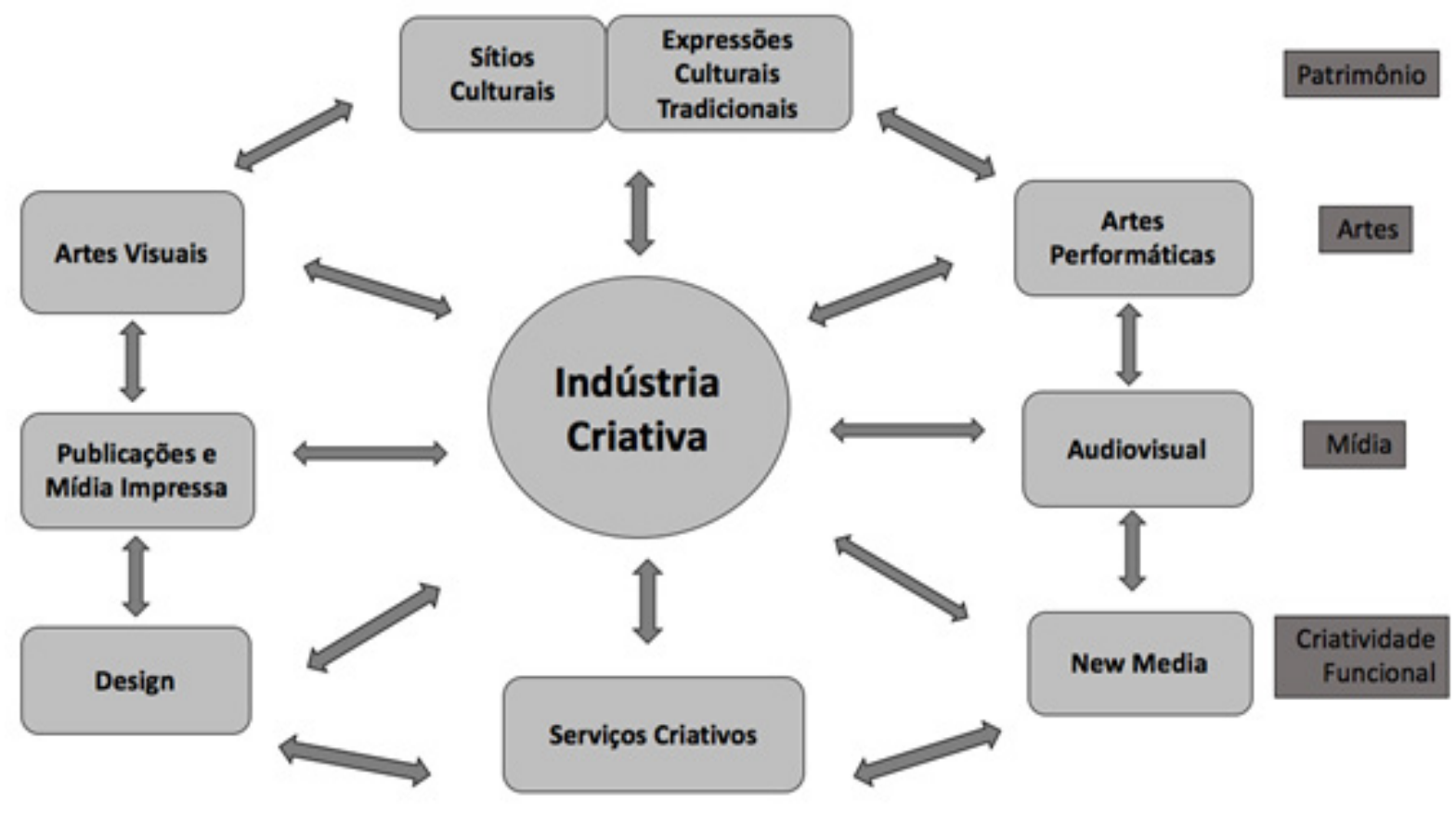

Fonte: UNCTAD (2010)

As indústrias criativas são os ciclos de criação, produção e distribuição de produtos e serviços que utilizam criatividade e capital intelectual como insumos primários; constituem um conjunto de atividades baseadas em conhecimento, focadas, entre outros, nas artes, que potencialmente gerem receitas de vendas e direitos de propriedade intelectual; constituem produtos tangíveis e serviços intelectuais ou artísticos intangíveis, com conteúdo criativo, valor econômico e objetivos de mercado; posicionam-se no cruzamento entre os setores artísticos, de serviços e industriais; e constituem um novo setor dinâmico no comércio mundial (UNCTAD, 2010).

Todo o processo de cidades criativas é resultado de processos maiores, como a globalização e a reação natural de valorização do que é diferencial, a exemplo das identidades e culturas locais; a dispersão acelerada das tecnologias de informação e comunicações; a divulgação das estatísticas de que mais da metade da humanidade já vive em cidades; a valorização econômica dos ativos culturais das cidades, pela diversidade e identidades culturais; a expansão das tecnologias de informação e comunicações; e a fragmentação global das cadeias produtivas (REIS, 2011). 
O termo Turismo Criativo foi mencionado por Pearce e Butler (1993) como um potencial nicho de turismo, apesar de eles não terem definido o conceito. E então, o conceito de turismo criativo foi identificado pela primeira vez como um nicho específico do turismo por Greg Richards e Crispin Raymond (2000): o turismo que oferece aos visitantes a oportunidade de desenvolver seu potencial criativo através da participação ativa em cursos e experiências que são característicos do destino (RICHARDS; RAYMOND, 2000; RICHARDS, 2011).

Destaca-se a importância do turismo entre os fatores geradores de desenvolvimento, porque os turistas buscam experiências por meio do consumo de produtos no local da produção (FLORIDA, 2002; JOFFE, 2011). Dessa forma, no turismo criativo, a criatividade deve ser considerada atributo importante do processo de produção e do processo de consumo (RICHARDS, 2003), sendo não somente a formalização do aprendizado por meio das experiências e das vivências locais, mas também uma forma de oferecer oportunidades aos turistas de participarem do cotidiano e da vida urbana (RAYMOND, 2007), adequandose à evolução dos processos de produção e de consumo vigentes (ASHTON, 2018).

De acordo com Horodyski (2014), o processo de consumo de souvenirs está diretamente relacionado com as experiências e as atitudes dos visitantes em relação ao espaço urbano, de forma emocional e racional, conforme as experiências de consumo de cada turista, onde:

A proximidade entre os estabelecimentos de comercialização destes produtos e os espaços de maior circulação de turistas é notória na maior parte dos destinos turísticos do mundo, evidenciando-se, assim, o desejo dos visitantes de consumirem objetos como lembranças das experiências turísticas vividas em um determinado espaço urbano ou natural (HORODYSKI, 2014, p. 19).

Destaca-se, ainda, que no turismo criativo ocorre a criação de algo conjunto (cocriação), que promove o desenvolvimento de novas habilidades em função de valores e de conhecimentos anteriores, durante a atividade turística, que agregam novos valores ao consumo do produto turístico, pois tem por base a coprodução e a coparticipação (RICHARDS; WILSON, 2005; RICHARDS, 2011; ASHTON; VALDUGA; TOMAZZONI, 2015).

Desta forma, os turistas se transformam e se tornam cocriadores das destinações turísticas, aumentando a vitalidade e a vivacidade das cidades, abrangendo novas áreas de conexões culturais e de criatividade (MIKULSKI; LIMBERGER; ANJOS, 2018). A experiência de consumo é intrínseca à atividade do turismo (HORODYSKI, 2014), onde essas experiências estão relacionadas a status, lembranças, valor de troca, raridade, e os produtos também podem ser marcadores da memória (SOLOMON, 2002), como os souvenirs (HORODYSKI, 2014). 


\section{SOUVENIR COMO ESTRATÉGIA}

A oferta de souvenirs existe desde o início da atividade turística, quer disponivel em mercados ao ar livre, na Europa, no século XVIII, época em que o turismo é marcado pelo Grand Tour, ou já no século XX, em cartões postais, em réplicas dos monumentos mais conhecidos e todo tipo de objeto com a inscrição "lembrança de..." (SCHLÜTER, 1998).

Verifica-se que, na prática do turismo, os registros de viagem são importantes para se autenticar uma experiência vivida em um destino turístico (STEWART, 1993), quer sejam diários, fotografias ou filmagens. Assim, as experiências dos turistas podem ser registradas também em objetos e autenticar uma vivência no destino, concretizando-se como uma lembrança trazida de situações de viagem, nomeadamente consideradas souvenirs.

Os souvenirs podem ser denominados objetos abstratos que recriam as experiências dos turistas (MORGAN; PRITCHARD, 2005), pois as lembranças como objetos mediam as experiências no tempo e no espaço e, se bem concebidas, deixam impressões positivas aos turistas em relação ao destino turístico visitado (CHUNXIAO; TINGYNE, 2010).

Em resumo, para Horodyski (2014) os souvenirs representam, materialmente, um determinado destino turístico e, imaterialmente, as experiências, memórias e lembranças de cada turista consumidor destes produtos. Estes objetos são capazes de tangibilizar as experiências dos turistas, estando, portanto, relacionados ao consumo experiencial, no qual a sua função ficaria em segundo plano, prevalecendo o seu valor simbólico, que é individual e subjetivo (HIRSEHMAN; HOLBROOK, 1982; FEATHERSTONE, 1995; SOLOMON, 2002).

Além de ser um componente essencial e significante da experiência de viagem (MEDEIROS; CASTRO, 2007), o souvenir no turismo também é trazido como presente. O turista, ao retornar da viagem, presenteia e descreve suas experiências a outras pessoas, apresentando e contando onde comprou o souvenir; compartilhando as experiências da viagem realizada (GORDON, 1986). Assim, o valor do souvenir está na narrativa possivel de ser realizada em torno de si e do seu local de origem (STEWART, 1993), ainda que os registros e objetos possuam um significado afetivo somente para o turista (GARCIA-MAS; GARCIA-MAS, 2005). Contudo, trazer presentes de viagem faz parte de um rito de retornar e se reintegrar à sociedade (GORDON, 1986).

Os souvenirs são, em geral, produtos dotados de bom humor, pois o seu consumidor encontra-se, em grande parte, de férias, divertindo-se, sem trabalho e sem tanta preocupação em poupar dinheiro (GORDON, 1986). Com efeito, o contexto do momento da compra de um souvenir é particular e parte da experiência da viagem, vez que corresponde à atitude do turista naquele momento e naquele local 
(NYFFENEGGER; STEFFEN, 2010). Evidencia-se que a inovação e a diferenciação, que por muito tempo foi feita por atributos do produto e do consumidor, hoje é baseada na experiência do consumo, o uso propriamente dito relacionado à emoção e na circunstância da compra (CARNIATTO, 2008).

Sendo assim, Shen (2011) afirma que os turistas entendem e valorizam um produto local, mas, não sendo eles etnólogos, muitas vezes consomem outros bens porque simplesmente desejam, e isso não pode ser considerado uma atitude negativa. Ele classifica os souvenirs como 'culturais' e/ou 'comerciais'. Nyffenegger e Steffen (2010) afirmam que muitos turistas compram souvenirs com um sentimento de desprezo pelo produto, por considerá-los banais ou objetos de qualidade inferior, mas, ainda assim, os compram, pois essa ação faz parte da experiência turística. Destaca-se ainda que a percepção ou experiência que o consumidor tem com o objeto passa inevitavelmente pelo design (CARNIATTO, 2008; SEBRAE, 2017).

Portanto, concorda-se com Gordon (1986) que afirma que qualquer produto que o turista leve como lembrança é um souvenir do destino turístico, mesmo que este produto não seja local, pois o turista pode ou não ter interesse em buscar por autenticidade e por produtos locais. Tais aspectos, relacionados ao modo como, onde e porque ocorre o consumo de souvenirs, decorrem, em parte, do perfil do turista e de suas motivações no destino turístico (SHEN, 2011).

\section{DESTINO TURÍSTICO CURITIBA}

Curitiba, a capital do Estado do Paraná, fundada em 1693, é conhecida internacionalmente por seu planejamento urbano, seus programas ambientais e o sistema de transporte público, elementos que deram destaque à cidade no cenário nacional e internacional. Isto é reflexo de anos de trabalhos de planejamento urbano na capital paranaense, resultados dos impactos de instrumentos de planejamento como os Planos Diretores, Planos Setoriais, dentre outros (IPPUC, 2004; DOMARESKI-RUIZ; FERNANDES; GANDARA, 2014).

É um destino turístico urbano, que faz parte da Região Turística Rotas do Pinhão - Curitiba e Cidade Metropolitana. A imagem turística da cidade está associada ao seu planejamento urbano (MOURA 2007; SANCHEZ, 1999) e, principalmente, a alguns de seus parques, como o Jardim Botânico e a Ópera de Arame, ou a atrativos culturais, como o Museu Oscar Niemeyer, refletindo-se, assim, na imagem dos souvenirs ofertados pelos estabelecimentos comerciais destes produtos (HORODYSKI, 2014).

Com uma população de 1.893.997 habitantes (IMT, 2018), apresenta $52 \mathrm{~m}^{2}$ de área verde por habitante (IMT, 2019), 37 parques e bosques urbanos, 454 praças e mais de $200 \mathrm{~km}$ de ciclovias, sendo reconhecida por ser eco friendly, com uma vasta área verde e uma grande oferta de pontos turísticos que atraem a atenção dos turistas que visitam a cidade. 
É reconhecida nacional e internacionalmente, tanto por seus visitantes como pela população local, por ser uma cidade com qualidade de vida, por ser planejada e possuir uma infraestrutura considerada diferenciada e inovadora (FERNANDES; SOUZA; TONON; GÂNDARA, 2014). Cabe destacar a importância da imagem que o turista possui a respeito de um destino turístico, como ressalta Gândara (2008), lembrando que a percepção da imagem turística é individual, porque se relaciona diretamente com a experiência de cada visitante no destino (CAMARGO; CRUZ, 2009; HORODYSKI, 2014).

\section{ANÁLISE DO PROJETO SOUCURITIBA}

Atualmente, na economia mundial, o conhecimento, a cultura e a criatividade são fatores de competitividade entre países e cidades. E neste movimento global, a criatividade envolvida no processo de desenvolvimento de um produto ou atividade é um fator significativo, onde o setor criativo é um formador de inovação econômica e social porque o setor tem grande potencial para impactar outras áreas com soluções práticas e econômicas.

O SouCuritiba se autodefine como sendo um projeto de economia criativa que fomenta 0 desenvolvimento de souvenirs inovadores, em busca de novas oportunidades de negócios para produtores locais. A missão do Projeto SouCuritiba é levar Curitiba para mais longe, com inovação e criatividade em souvenirs, onde sua visão é ser a marca referência de souvenirs criativos de Curitiba e "curitibanizar" o mundo (SouCuritiba, 2019; SEBRAE, 2017a).

O projeto é executado através de ação conjunta entre diversas entidades que compõem o chamado Grupo Gestor, tendo a função de discutir e definir assuntos de caráter estratégico e encaminhamentos operacionais para o projeto. Com a presença dos representantes das entidades parceiras: Instituto de Turismo de Curitiba - IMT; Fundação Cultural de Curitiba - FCC; Curitiba, Litoral e Região Convention \& Visitors Bureau - CCVB; Universidade Federal do Paraná - UFPR; Centro Brasil Design - CBD e o SEBRAE-PR. Esse Grupo Gestor participa ativamente de reuniões, organiza treinamentos para os participantes do projeto e atua de maneira integrada para colaborar com o processo de inovação e criatividade dos participantes. Todos esses envolvidos têm como foco promover a cidade de Curitiba ajudando a torná-la um destino turístico cada vez mais atraente e competitivo no cenário nacional e internacional (SOUCURITIBA, 2019; SEBRAE, 2017a).

Cada entidade apoia, dentro de seu escopo e de seus recursos, a realização das ações práticas para a viabilização de cada edição. Este apoio abrange a disponibilização de profissionais, equipamentos ou de espaços físicos; colaboração na divulgação e promoção do projeto; compartilhamento de informações e oportunidade para produtores; entre outros. Sendo o aporte financeiro, para pagamentos de profissionais, impressão de materiais e outros custos, realizado pelo SEBRAE/PR. 
O SouCuritiba começou a ser idealizado em 2012, a partir da demanda do Projeto SEBRAE 2014, que tinha como objetivo potencializar negócios para micro e pequenas empresas a partir das oportunidades geradas pela Copa do Mundo FIFA realizada no Brasil. Considerado um evento potencializador de fluxo turístico, o Ministério do Turismo levantou diversas oportunidades de negócios relacionadas aos chamados produtos associados ao turismo, tais como artesanato, artigos de ornamentação e vestuário e a própria economia criativa (SEBRAE, 2014; 2017a; MTUR, S/D).

No primeiro ano da sua estruturação, o projeto realizou uma pesquisa de oferta de souvenir em Curitiba. A pesquisa foi aplicada por uma consultora especializada que coletou informações a partir de um questionário em visitas realizadas à maioria das lojas de souvenirs de Curitiba. Essa pesquisa demonstrou que os produtos oferecidos naquele momento eram pouco atrativos e pouco inovadores, dando força à iniciativa de criação do SouCuritiba.

\section{Quadro 01 - Dados do Projeto SouCuritiba}

\begin{tabular}{|c|c|}
\hline Início do Projeto & $\begin{array}{l}2012 \text { início do planejamento; } \\
2013 \text { realização da primeira edição. }\end{array}$ \\
\hline Missão & $\begin{array}{l}\text { Levar Curitiba para mais longe, "curitibanizando" corações, com inovação e } \\
\text { criatividade. }\end{array}$ \\
\hline Objetivo & $\begin{array}{l}\text { O Projeto SouCuritiba busca fomentar o setor de souvenirs como produto associado } \\
\text { ao turismo, através do apoio à produtores e criadores residentes em Curitiba e Região } \\
\text { Metropolitana na confecção de produtos inovadores e que representem a cidade de } \\
\text { Curitiba. } \\
\text { O Projeto SouCuritiba tem como objetivo: } \\
\text { I. Ter um conjunto de produtos souvenirs de qualidade, inspirado na identidade } \\
\text { curitibana; } \\
\text { II. Atender às necessidades e desejos do mercado turístico, materializando suas } \\
\text { experiências e fortalecendo Curitiba como destino; } \\
\text { III. Gerar negócios, ampliando as possibilidades de comercialização de pequenos } \\
\text { produtores locais. }\end{array}$ \\
\hline $\begin{array}{l}\text { Instituições } \\
\text { envolvidas }\end{array}$ & $\begin{array}{l}\text { SEBRAE/PR - Serviço de Apoio às Micro e Pequenas Empresas do Paraná; } \\
\text { FCC - Fundação Cultural de Curitiba; } \\
\text { IMT - Instituto Municipal de Turismo; } \\
\text { CCVB - Curitiba Região e Litoral Convention \& Visitors Bureau; } \\
\text { UFPR - Universidade Federal do Paraná; } \\
\text { CBD - Centro Brasil Design. }\end{array}$ \\
\hline
\end{tabular}




\begin{tabular}{|l|l|}
\hline Produtores & $\begin{array}{l}162 \text { produtores capacitados (ago/2018); } \\
70 \text { produtores comercializando (ago/2018) }\end{array}$ \\
\hline \multirow{3}{*}{ Produtos } & $\begin{array}{l}291 \text { produtos no catálogo (ago/2018); } \\
422 \text { produtos avaliados nas curadorias (ago/2018); } \\
63.000 \text { unidades de souvenirs vendidos; } \\
\text { R\$ 900.000,00 reais em vendas (dez/2017). }\end{array}$ \\
\hline \multirow{4}{*}{$\begin{array}{l}\text { Valores/Princípios } \\
\text { da Economia } \\
\text { Criativa }\end{array}$} & $\begin{array}{l}\text { Agrega profissionais da Classe Criativa tais como designers, arquitetos, artesãos, } \\
\text { ilustradores, publicitários, entre outros; }\end{array}$ \\
& Valoriza a cultura local, e suas singularidades, como elemento chave para a \\
& Transformaça e inovação nos produtos; \\
& Promove a troca de experiências e a cocriação no processo de inovação. \\
& Proporciona a criação de redes através da parceria entre empreendedores criativos, \\
& entidades envolvidas e comércio local e virtual. \\
\hline
\end{tabular}

\section{Fonte: elaboração própria (2019)}

Além disso, foi elaborado o Regulamento Interno do projeto e o primeiro planejamento estratégico do projeto nos quais foram definidas as entidades que iriam compor a gestão do mesmo e as ações futuras. Em 2013 foi realizada a primeira edição, que se repetiu anualmente até 2018, completando 6 edições ao todo. A edição de 2019 já está em fase de planejamento.

As ações do SouCuritiba junto aos participantes são realizadas em 4 fases:

\section{Fase 1 - Inscrição}

A partir de um convite aberto à toda a comunidade criativa de Curitiba e Região Metropolitana, os interessados se inscrevem e passam por uma seleção para o preenchimento das vagas disponiveis naquela edição. Para a inscrição não é necessário que o candidato apresente nenhum projeto de produto ou portfólio. Esta forma de seleção foi assim definida pois o candidato pode criar seu produto, uma vez que seja estimulado pelo processo. Após a divulgação da lista dos selecionados, para confirmar sua participação a pessoa deve comparecer a uma reunião e assinar um termo de aceite do Regulamento Interno (SEBRAE, 2017b).

\section{Fase 2 - Criação dos Souvenirs}

Esta fase é a mais importante e representativa das atividades do projeto junto aos empreendedores criativos, pois é neste momento que toda a carga de informações e estímulos para a criação é repassada. 
Também é neste momento que se estabelece o relacionamento do projeto com cada participante e entre eles. Muitas parcerias profissionais se estabelecem nestes encontros (SEBRAE, 2017b). Esta fase está dividida nas seguintes etapas:

\section{Etapa 1 - Empreendendo com o SouCuritiba}

Encontro em grupo - o objetivo desta etapa é ampliar o entendimento de conceitos básicos do turismo, mudar a forma de pensar o souvenir, conhecer possibilidades criativas e compreender 0 SouCuritiba como uma oportunidade para gerar negócios.

- Boas vindas oficiais do Grupo Gestor aos novos participantes;

- Palestras sobre turismo;

- Palestra sobre o souvenir como materialização de uma experiência turística;

- Apresentação de casos de sucesso.

\section{Etapa 2 - Conhecendo minha cidade}

Palestra - ocorre uma contextualização histórica da cidade com referência à arquitetura, monumentos, ruas, parques e demais atrativos da cidade.

Visita Guiada - passeio pela cidade no trajeto do ônibus turismo, quando possível realizado com o próprio ônibus que é reservado com exclusividade ao grupo. Um guia faz o acompanhamento da viagem trazendo mais informações e curiosidades sob a ótica do turismo. Estas atividades têm como objetivo apresentar a cidade com o olhar do turista, vivenciar as experiências dos turistas ao ver a cidade (sol, frio, pressa, fome, cansaço, contemplação, surpresa) e ampliar o repertório visual e histórico sobre a cidade.

- Palestra História de Curitiba;

- Visita Guiada pela cidade.

\section{Etapa 3 - Criando o souvenir de Curitiba \\ Oficina de design}

Palestra sobre o perfil do turista curitibano;

Atividade prática em grupos;

Palestra sobre possibilidades de se inserir referências locais nos produtos;

Atividade prática individual para iniciar a criação do novo souvenir.

Consultorias de design - atendimentos individualizados em 2 encontros para orientação em design dos produtores. São discutidos a inovação no produto, a referência com a identidade curitibana utilizada, preço e posicionamento, qualidade e viabilidade de produção. 0 intervalo entre a oficina de design e entre 
as duas consultorias deve ser utilizado pelo produtor para realizar os estudos e confecção de testes e mockups do produto que podem ser apresentados nas consultorias para facilitar a orientação.

Oficina de Embalagem - sensibilização para a utilização racional e criativa de embalagens nos produtos. Necessidade de inserir a identificação do produtor, do projeto e de informações técnicas e comerciais. Análise conjunta e/ou individual da proposta de embalagem dos produtos em processo de criação.

Os objetivos desta etapa são conhecer o perfil do turista curitibano, desenvolver produtos direcionados às necessidades e desejos do consumidor turista, ampliar o repertório de maneiras como utilizar os elementos da identidade local em produtos e discutir e avaliar de forma colaborativa, entre produtores e especialistas, as propostas de produtos e embalagens.

\section{Etapa 4 - Conhecimentos complementares}

Oficina de precificação e vendas - repasse de conhecimentos sobre estratégia de preço, técnicas de precificação, políticas de desconto e negociação.

Oficina de atitude empreendedora - sensibilização sobre atitudes necessários ao empreendedor e crenças limitantes que impedem o sucesso de um negócio.

Na etapa 1, a programação pode ser alterada conforme surgirem temas que podem colaborar para ampliar o repertório do grupo. Isso também impacta no tempo necessário para a realização do encontro, que pode ser de 5 a 8 horas para sua realização. Na etapa 2, as duas atividades se complementam, já que a visão histórica apresentada ao grupo por vezes é diferente da versão repassada ao turista pelo guia. A abordagem histórica também permite que a visita seja realizada com mais atenção aos detalhes, reforçando o entendimento do conteúdo.

Na etapa 3, as consultorias, além de orientar em termos de design os produtos, tem também a função de se certificar que haverá diversidade de produtos diante do mix já existente ou em criação, ou seja, minimizando a criação de muitos produtos similares ou repetidos. A etapa 4 compreende atividades complementares que podem ou não ser executadas conforme o perfil do grupo. Outras atividades ou temas para palestras e oficinas podem ser definidos conforme se julgar necessário.

\section{Fase 3 - Curadoria}

Após passar pelas etapas da fase 3, o produtor está munido de informação e orientação para criar um souvenir inovador e criativo. Para a realização da curadoria o produtor deverá entregar o produto finalizado ou um protótipo o mais próximo possível do produto final. O número de produtos que podem ser apresentados é definido no Regulamento Interno apresentado aos produtores já na fase de inscrição. 
Contudo, este número pode ser aumentado ou reduzido durante o processo, se assim deliberar o Grupo Gestor (SEBRAE, 2017b).

A curadoria acontece com a participação de ao menos um representante de cada entidade do Grupo Gestor. Quando há mais de um representante, estes votam em conjunto, já que cada entidade tem direito a apenas 1 voto, para manter a paridade entre as entidades. Podem ser convidados outros profissionais ou lojistas para participarem da curadoria conforme deliberar o Grupo Gestor. Os produtos são analisados um a um, por cada participante que registra em uma ficha de avaliação se aprova ou não aprova o produto. No caso de não aprovação é obrigatório que se registre o motivo da recusa, para que o produtor possa executar, se desejar, as alterações necessárias para submeter o produto a nova avaliação da curadoria na próxima edição do projeto (SEBRAE, 2017b).

Para ser aprovado, o produto deve ter maioria simples dos votos. As fichas de avaliação são contabilizadas e a lista com o resultado da curadoria é enviado aos produtores por e-mail. É realizada uma devolutiva para os participantes cujos produtos não foram aprovados, com a entrega do produto e um resumo das justificativas da recusa. Nós consideramos que, uma vez que o produtor passe pela fase de criação, mesmo que ele não tenha seu produto selecionado pela curadoria, ele já é um participante efetivo do projeto. Podendo colocar novos produtos para avaliação da curadoria numa nova edição (SEBRAE, 2017b).

Os avaliadores são pessoas com conhecimento em diversas áreas tal qual éa diversidade de entidades participantes do Grupo Gestor. Neste sentido, diversos aspectos são considerados para a curadoria, tais como prevê o Regulamento Interno: funcionalidade, capacidade produtiva mensal, acabamento, qualidade do emprego da técnica de execução, adequação ao mercado, valor e preço, relação com a identidade local, estética, segurança de uso do produto, sustentabilidade dos materiais empregados, adequação do produto de forma a não constranger, discriminar ou ofender qualquer pessoa, gênero, raça ou classe e estar de acordo com a legislação vigente (SEBRAE, 2017b).

\section{Fase 4 - Comercialização}

Os produtos aprovados passam a compor a coleção SouCuritiba. As próximas etapas são as seguintes:

Fotos dos produtos e produtores - todos os produtos e os produtores são fotografados em estúdio. As fotos passam a compor um banco de imagens que será utilizado na divulgação dos produtos e do projeto.

Rodada de negócios - é o momento em que os Pontos de Venda Credenciados são convidados a conhecerem, em primeira mão, os novos produtos da coleção. Este formato de encontro propicia 
a aproximação do produtor com o parceiro que irá comercializar os produtos e pode gerar, já neste momento, as primeiras vendas. Para a maioria dos produtores é a oportunidade de fazer contatos e agendar reuniões para negociações. Tradicionalmente, na rodada cada produtor apresenta seu produto num espaço e os pontos de venda passam para conhecer cada um. Mas também já experimentamos inverter essa configuração, num formato no qual cada produtor faz uma rápida apresentação chamada de Pitch. Posteriormente, promove-se o network no momento do café. Isso aconteceu em 2016, quando tivemos uma edição especial (SEBRAE, 2017b).

Evento de lançamento - o evento de lançamento dos produtos tem a finalidade de apresentar ao mercado os produtos resultantes da edição vigente do projeto e gerar mídia espontânea para promover os produtos. Para tanto, cada entidade mobiliza sua assessoria de imprensa para que acione os mais diversos meios de comunicação a fim de que compareçam ao evento e publiquem conteúdos relacionados aos projetos. $\mathrm{O}$ evento geralmente acontece em um local cedido por um dos parceiros, os produtos são expostos de forma a valorizá-los e o ambiente é decorado para isso. Os diretores e presidentes das entidades parceiras são convidados a prestigiar. Também autoridades são convidadas, como o Prefeito que esteve presente no lançamento da coleção de 2017. O Lançamento também tem a função simbólica de confraternização e comemoração dos resultados obtidos no processo pelo qual os participantes e profissionais envolvidos passaram. É o encerramento de um ciclo, mas não o término das atividades, visto que a partir daí os produtores continuam em contato com o projeto e com os pontos de venda para a comercialização dos produtos (SEBRAE, 2017b). 
Figura 02 - Resumo das Etapas do Projeto SouCuritiba

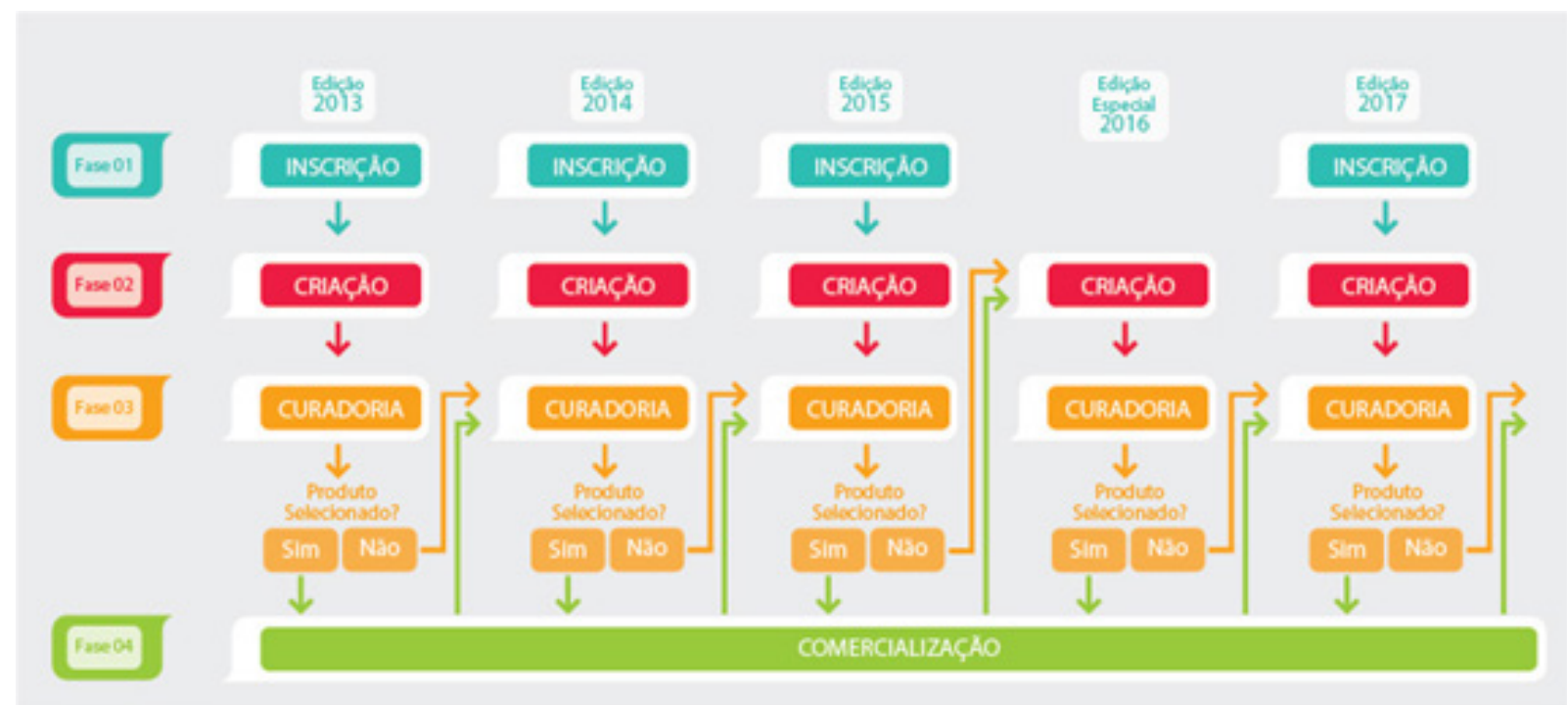

Fonte: SouCuritiba (2019)

Além das fases realizadas a cada nova edição, existes ações que acontecem em paralelo, de forma permanente, no SouCuritiba (SEBRAE, 2017b), tais como:

- acompanhar o andamento das vendas, solicitando relatórios aos parceiros comerciais;

- realizar visitar aos Pontos de Venda Credenciados;

- gerar relatórios de vendas e apresentar ao Grupo Gestor;

- selecionar e avaliar novos pontos de venda;

- criar e confeccionar materiais de divulgação do projeto, tais como folders, banners e etiquetas;

- criar e confeccionar materiais para sinalização nos Ponto de Venda, tais como displays, móbiles, adesivos e etiquetas;

- criar material para divulgação das inscrições, tais como imagens para e-mail, banners para sites, imagens para postagem em redes sociais, imagens de capa e perfil em redes sociais etc.

- criar e realizar campanhas e ações de divulgação específicas, tais como as de Natal, no mobiliário urbano da cidade;

- confeccionar o catálogo de produtos e realizar sua atualização;

- alimentar com informações o site e as mídias sociais do SouCuritiba; 
- manter comunicação constante com produtores, pontos de venda e entidades parceiras;

- organizar pautas das reuniões do grupo gestor, bem como a memória escrita das mesmas.

Figura 03 - Resumo dos resultados

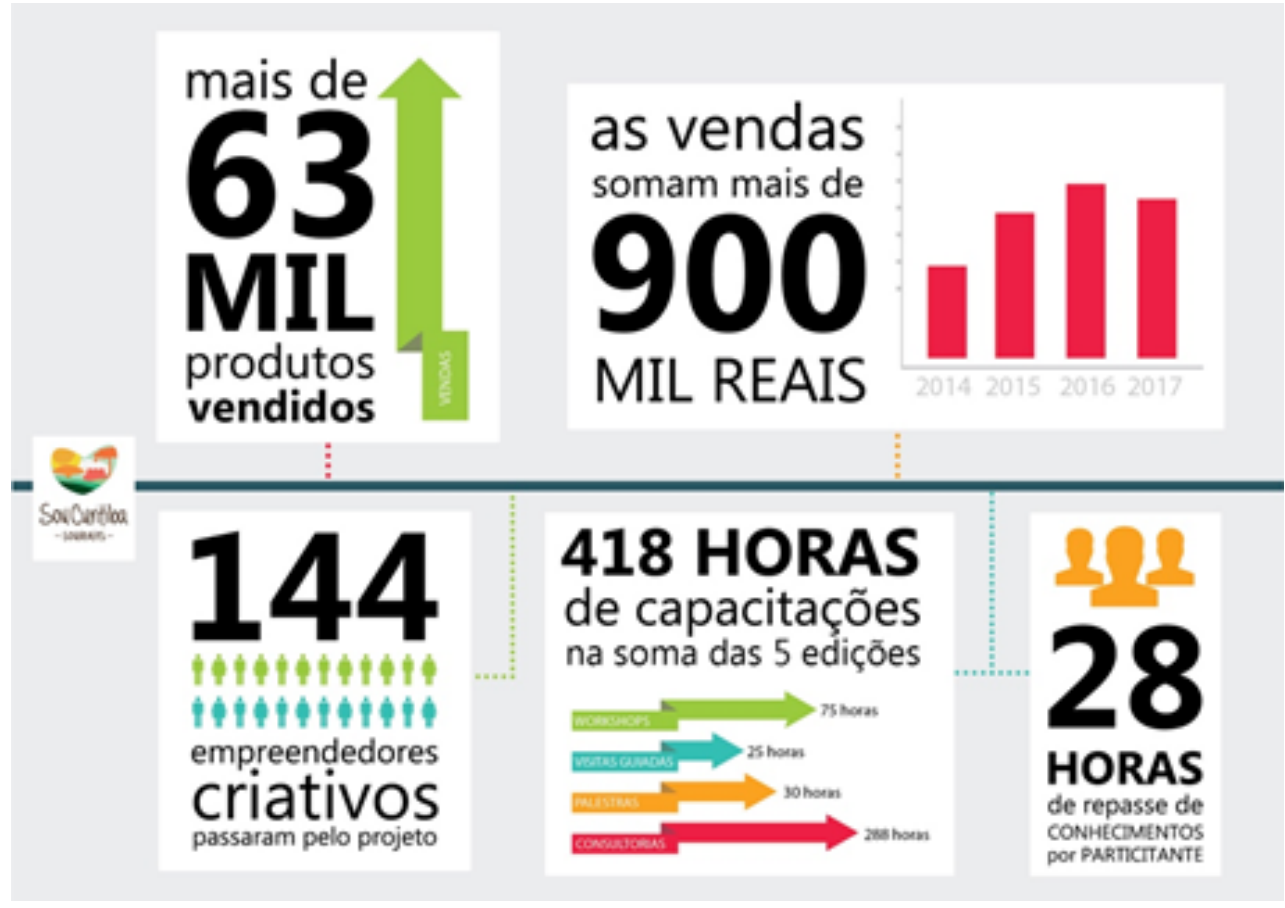

Fonte: SouCuritiba (2017)

O Projeto SouCuritiba está ativo desde 2013 e, com o Grupo Gestor, determina e organiza as ações a cada ano, apresentando resultados positivos tanto para os participantes do projeto quanto para os consumidores e para o destino turístico de Curitiba.

A melhoria dos produtos, em termos de inovação, criatividade e funcionalidade e a melhoria dos negócios, no que se refere ao atendimento, à ambientação, à apresentação dos produtos e ao encantamento do cliente/turista, são elementos que estão sempre sendo avaliados (SEBRAE, 2014) e que representam um grande diferencial para o souvenir da cidade (CARNIATTO, 2008; HORODYSKI, 2014). 


\section{CONSIDERAÇÕES FINAIS}

Todo o processo de transformação das cidades impactou diretamente no modo de vida da população, no modo de produção e principalmente no modo de consumo (ASHTON, TOMAZZONI, EMMENDOERFER, 2014), onde, segundo Ashton (2018), a "criatividade foi a principal responsável por acelerar o processo de desenvolvimento de cidades e regiões, a mesma passou a ser a nova moeda mundial".

Neste contexto, 0 turismo criativo é fundamental também porque agrega à oferta turística novas possibilidades de interação e de aprendizado para os turistas (ASHTON, 2018), valorizando a experiência, fator significativo para o novo modo de consumo (SOLOMON, 2002; SWARBROOKE; HORNER, 2002; HORODYSKI, 2014).

O turismo é um meio de promover os lugares, sua imagem, sua cultura e atrair investidores (DAS; DIRIENZO, 2010), assim como este público de pessoas criativas, para visitar ou estabelecer suas atividades (PECK, 2005), valorizando o destino turístico. Para desenvolver atividades e experiências criativas, não basta criar cenários e histórias prontas, é preciso permitir que os participantes tenham autonomia para criar suas próprias narrativas e possam desenvolver seu potencial criativo. Os turistas precisam ser munidos de meios para construir uma experiência única de forma mais sustentável (MIKULSKI, LIMBERGER, ANJOS, 2018).

A cadeia produtiva do souvenir, em Curitiba, existe e precisa ser melhor compreendida, desde os produtores/artistas que confeccionam as peças, passando pelos fornecedores dos materiais até chegar aos empresários que comercializam os produtos e têm o contato direto com o cliente/turista, além dos outros empreendimentos envolvidos nessa cadeia e que têm papel fundamental de promoção e auxílio à comercialização dos produtos (SEBRAE, 2014).

A busca pelo entendimento e tangibilização da identidade curitibana vem cada vez mais sendo discutida, apresentada e consumida pelos curitibanos e pelos visitantes e é nessa "onda" que o projeto e seus parceiros devem embarcar, buscando ser um elemento real de diferenciação em todo o processo de mudança que a capital vive em termos de cultura, criatividade e interação social (SEBRAE, 2014).

O Projeto SouCuritiba potencializa e evidencia a criatividade, a inovação e a oportunidade de atualização a todos os participantes, levando o destino turístico Curitiba em forma de souvenirs a todos os que consomem seus produtos. 


\section{REFERÊNCIAS}

ANDERSSON, A. Criatividade e desenvolvimento regional. Regional Science. 56, p. 5-20, 2005.

ASHTON, M. S. G. Cidades Criativas: análise reflexiva das relações com o Turismo. In: Dusan Schreiber. (Org.). Inovação e Aprendizagem Organizacional. Novo Hamburgo: Feevale, v. 1, p. 230- 245, 2013.

ASHTON, M. S. G. Por que ser uma cidade criativa? Implicações com o Turismo. Turismo e Cidades Criativas. Francisco Antonio dos Anjos, Newton Paulo Angeli, Thays Cristina Domareski Ruiz (orgs.). Itajaí: UNIVALI, 2018.

ASHTON, M. S. G.; TOMAZZONI, E. L.; EMMENDOERFER, M. L. Elementos para a validação de cidades criativas como destinos turísticos competitivos. Turydes, v.7, n.17, 2014.

ASHTON, M. S. G.; VALDUGA, V.; TOMAZZONI, E. L. Turismo criativo e desenvolvimento da oferta turística do cluster do Vale dos Vinhedos (RS, Brasil). Investigaciones Turísticas, v.10, p. 90-116, 2015.

CAIADO, A. S. C. (Coordenador). Economia Criativa na Cidade de São Paulo: Diagnóstico e Potencialidade. São Paulo: FUNDAP, 2011.

CAMARGO, P. , CRUZ, G. Marketing Turístico para Cidades Culturais. In: CAMARGO, P. , CRUZ, G. Turismo Cultural - estratégias, sustentabilidade e Tendências. Ilhéus: ed. EDITUS, 2009.

CARNIATTO, I. Gestão de design e artesanato: uma abordagem com base na pesquisa-ação. 2008. 147 f. Dissertação (Mestrado em Design) Programa de Pós Graduação em Design - Linha Sistemas de Produção e Utilização, Universidade Federal do Paraná, Curitiba, 2008.

CHIM-MIKI, A.F. DOMARESKI-RUIZ, T.C. Competitividade e o Potencial da Cidade Criativa Turística: Uma Proposta de Avaliação. Francisco Antonio dos Anjos, Newton Paulo Angeli, Thays Cristina Domareski Ruiz (orgs.). Itajaí: UNIVALI, 2018.

CHUNXIAO, C; TINGYNE, K. Research on the Development of Tourism Souvenirs Based on Experience Design. International Conference on System Science, Engeneering Design and Manufacturing Informatization. College of Computer Science and Information, Guizhou University. Yichang, China, 2010.

DAS, J.; DIRIENZO, C. Tourism competitiveness and corruption: A cross-country analysis. Tourism Economics, v.16, n.3, p. 477-492, 2010.

DOMARESKI-RUIZ, T.C. ; FERNANDES, D. L. ; GÂNDARA, J.M.G. . A contribuição do planejamento urbano na imagem e na competitividade do destino turístico de curitiba (PR). Caderno Virtual de Turismo (UFRJ) , v. 14, p. 150-166, 2014. 


\section{Gestãoe \\ Desenvolvimento}

e-ISSN: 2446-6875

p-ISSN: 1807-5436

EMMENDOERFER, M. L.; Ashton, M. S. Territórios Criativos e suas Relações com o Turismo. Revista Turismo \& Desenvolvimento,3(21/22),p. 139-151,2014.

FEATHERSTONE, M. Cultura de Consumo e Pós-modernismo. São Paulo: Studio Nobel, 1995.

FERNANDES, D. L.; SOUZA, T. A.; TONON, L. M. P. ; GANDARA, J. M. G. A paisagem urbana e a formação da imagem turística da cidade de Curitiba/PR: a percepção de visitantes e visitados. Revista Hospitalidade, v.11, n.1, 45-63, 2014.

FLORIDA, R. The Rise of the Creative Class: And How It is Transforming Work, Leisure, Community and Every Day life. New York: Basic Books, 2002.

GANDARA, J. M. G. A imagem dos destinos turísticos urbanos. Revista Turismo Cultural. USP. Número Especial. São Paulo: 2008.

GIL, A. C. Métodos e Técnicas de Pesquisa Social. 5. ed. São Paulo: Atlas, 1999.

GORDON, B. The Souvenir: Messenger of The Extraordinary. Journal of Popular Culture, n.20, v.3, 135146, 1986.

HIRSEHMAN, E.C.; HOLBROOK, M.B. The Experimental Aspects of Consumption. The Journal of Consumer Research. v. 9, n. 2, 1982.

HORODYSKI, G.S. O Consumo na Experiência Turística: o caso dos souvenirs no destino Curitiba-PR. Tese de Doutorado. Programa de Pós Graduação em Geografia. Universidade Federal do Paraná. Curitiba, 2014

HOWKINS, J. The Creative Economy - how People make money from ideas. Londres: Penguin Books, 2001.

IPPUC. Instituto de Pesquisa e Planejamento Urbano de Curitiba. Disponivel em:<http://www.ippuc.org. $\mathrm{br} />$. Acesso em janeiro de 2019.

IMT. Instituto Municipal de Turismo. Disponível em: <www.turismo.curitiba.pr.gov.br>. Acesso em janeiro de 2019.

JOFFE, A. Cidades criativas ou bolsões criativos: reflexões da África do Sul. In Reis, A. C. F. \& Kageyama, P. (2011). Cidades Criativas: perspectivas. São Paulo: Garimpo de Soluções (59-69), 2011.

Landry, C. (2013). Origens e Futuros da Cidade Criativa. São Paulo: SESI-SP. 
LÜDKE, M.; ANDRÉ, M. E.D.A. Pesquisa em educação: abordagens qualitativas. São Paulo: EPU, 1986.

MEDEIROS J. H.; GRAND J. J.; FIGUEIREDO, J. L. A importância da economia criativa no desenvolvimento econômico da cidade do Rio de Janeiro. Coleção Estudos Cariocas. Rio de Janeiro, IPP, 2011.

MEDEIROS, F. B.; CASTRO, C. A Cidade e seus Souvenirs: O Rio de Janeiro para o turista ter. Revista Brasileira de Pesquisa em Turismo. v. 1, n. 1, p. 34-53, set. 2007.

MINISTÉRIO DO TURISMO. Proposta Estratégica de Organização Turística da Copa do Mundo 2014 Brasil. S/D. Disponivel em: <http://www.turismo.gov.br/sites/default/turismo/o_ministerio/publicacoes/ downloads_publicacoes/BRASIL_final_NOVO.pdf> Acesso em: 30 de fevereiro de 2019.

MIKULSKI, D. LIMBERGER, P. F. ANJOS, S. G. Cidades Criativas: o caso de Balneário Camboriú. Turismo e Cidades Criativas. Francisco Antonio dos Anjos, Newton Paulo Angeli, Thays Cristina Domareski Ruiz (orgs.). Itajaí: UNIVALI, 2018.

Miranda, R. (2009). [Rio] Cidade Criativa: cultura como quarto pilar do desenvolvimento. Fórum Internacional Rio Cidade Criativa. Disponível em: <http://cidadecriativa.org/download/Rio_Cidade_Criativa_Cultura_como_Quarto_Pilar_do_Desenvolvimento.pdf >

MORGAN, N., PRITCHARD, A. On Souvenirs and Metonymy Narratives of Memory, Metaphor, and Materiality. Tourist Studies. Vol. 5 no 1, 2005.

MOURA, R. O turismo no projeto de internacionalização da imagem de Curitiba. Turismo - visão e ação. UNIVALI. Vol 9, n.3. Itajaí: Editora Univali. P. 341-357, 2007.

NYFFENEGGER, F.K.; STEFFEN, D. Souvenirs - local messages. An exploration from the design Perspective. In: CHEN, L.; DJAJADININGRAT, T.; FEIJS, L.; KYFFIN, S. DESFORM 2010 - Design and Semantics of Form and Movement. Lucerne, Suiça, 2010.

OMT. Tourism for Development - Volume I: Key Areas for Action, 2018.

PECK, J. Struggling with the creative class. International Journal of Urban and Regional Research, v. 29, n. 4, p. 740-770, 2005.

RAYMOND, C. Creative Tourism New Zealand: The pratical challenges of developing creative tourism. Tourism, Creativity and Development, Routledge, Londres, 2007.

REIS, A.C.F. Cidades Criativas, burilando um conceito em formação. lara Revista de Moda, Cultura e Arte, p. 127-139, 2011. 


\section{Gestãoe \\ Desenvolvimento}

e-ISSN: 2446-6875

p-ISSN: 1807-5436

REIS, A. C. F. Cidades Criativas: da teoria à prática. São Paulo. SESI-SP editora. 2012.

REIS, A.C.F.; KAGEYAMA, P. Creative City Perspectives. São Paulo: Garimpo de Soluções e Creative City Productions, 2009.

RICHARDS, G. (2003). Turismo creativo: ¿una nueva dirección estratégica? In Ortega, E. (ed).Investigación y estrategias turísticas. Madrid: Thomson, (107-122).

RICHARDS, G. Creativity and Tourism - The State of Art. Annals of Tourism Research, v.38, n.4 p. 1225$1253,2011$.

RICHARDS, G; RAYMOND, C. Creative tourism, ATLAS News, 23: 16-20, 2000.

RICHARDS, G.,WILSON, J. Developing creativity in tourist experiences: A solution to the serial reproduction of culture? Tourism Management, 27, 1209-1223, 2005.

RICHARDSON, R. J. Pesquisa Social: Métodos e Técnicas. São Paulo, Atlas, 1999.

SÁNCHEZ, F. Políticas urbanas em renovação: uma leitura dos modelos emergentes. Revista Brasileira de Estudos Urbanos e Regionais, Campinas, n.1, p. 115- 132, 1999.

SCHLUTER, R.G. The role of T-Shirts in the Creation of Tourists destination Images. Revista Estudios y Perspectivas en Turismo. vol. 07, 1998.

SEBRAE. Cartilha do Tour da Experiência elaborado pelo Instituto Marca Brasil por solicitação do Ministério do Turismo e SEBRAE - 2010.

SEBRAE. Relatório da pesquisa de oferta de souvenir em Curitiba, 2014.

SEBRAE. Relatório de pesquisa SouCuritiba. Curitiba, 2017a.

SEBRAE. Regulamento Interno SouCuritiba. Curitiba, 2017b.

SHEN, M.J. The Effects of Globalized Authenticity on Souvenir. International Journal of Innovative Management, Information \& Production. v.2, n. 1, 2011.

STEWART, S. On Longing - narratives of the miniature, the gigant, the souvenir, the collection. Durhan: Duke University Press, 1993.

SOLOMON, M. R. 0 Comportamento do Consumidor - comprando, possuindo e sendo. Porto Alegre: Bookman, 2002. 
SWARBROOKE, J.; HORNER, S. O Comportamento do Consumidor no Turismo. São Paulo: ed. Aleph, 2002.

SOUCURITIBA. http://sites.pr.sebrae.com.br/soucuritiba/. Acesso em 10 de janeiro de 2019.

UNCTAD - UNITED NATIONS CONFERENCE ON TRADE AND DEVELOPMENT, Creative economy report 2010. Creative economy: a feasible development option. U.N., 2010

VIVANT, E. 0 que é uma cidade criativa? São Paulo, SP: SENAC, 2012. 